\title{
Teaching Reform and Practice of Rotation Classroom on "C Language Program Design" based on Interesting and Practice
}

\author{
Jingxian Wang ${ }^{1, a}$, Shijie Zhang ${ }^{2, b}$, Chunqiang $\mathrm{Li}^{3, \mathrm{c}}$ \\ ${ }^{1}$ Basic Teaching and Research Institute, Bohai University, Jinzhou, 121013, China \\ ${ }^{2}$ College of Finance and Trade, Bohai University, Jinzhou, 121013, China \\ ${ }^{3}$ School of Information Management, Beijing Information Science and Technology University, \\ Beijing, 100101, China \\ awjx_0610@126.com, b2824834538@qq.com, '642510571@qq.com
}

Keywords: interesting; practical; C language program design; rotation classroom; teaching reform; teaching practice

\begin{abstract}
C language program design" is a public foundation course in non-computer professional of science technology, through the study of this course, makes the students master the general methods of structured programming. Aiming at the existing problem of $\mathrm{C}$ language course teaching, this paper aims to explore a suitable for "language $C$ program design" course the rotation of the classroom teaching mode, the interesting case applied to the teaching practice of boring, and combined with practical, so as to stimulate students' interest in learning, improve the comprehensive quality and ability of students. Through the analysis of "turn the classroom" teaching model, combined with the characteristics of "C language program design" course, puts forward the concrete reform and practice of the plan, including learning case design, classroom teaching mode, teaching design and practice and the study effect evaluation and so on four steps.
\end{abstract}

\section{Introduction}

$\mathrm{C}$ language is a computer programming language, the characteristics of both the high-level language, and the assembly language. As a system design language, can write work system application, can also be used as an application design language, writing does not rely on the application of computer hardware, wide range of applications. C language course is a public basic course of computer science, through the study of this course, should make the students master the traditional structured programming method commonly. Based on the $\mathrm{C}$ language, trains the student to the rigorous program design idea, flexible way of thinking and strong ability. Based on this, let the students gradually master the complex software design and development method, for the follow-up professional courses of study to lay a solid foundation of theory and practice, therefore, this course is a course in theory and practice are strong. Teaching basic requirements: understand the characteristics of $\mathrm{C}$ language, USES the basic steps of $\mathrm{C}$ programming language and computer operation; master the $C$ language definition of various data types and methods of use; Grasp three basic structure of the $\mathrm{C}$ language, and simple program. To master the $\mathrm{C}$ language function, the definition of call and explain the method; Master $C$ language structure, document the concept and method of use of; Learn C language pointer, the concept and use of bit operations.

Interesting education is the person's psychology interest as the leading factor, to all-round development of people's psychological quality and improve people's learning fun for the purpose, based on the individual psychological characteristics of students, teachers in a targeted inspiration and guidance, let the student autonomy, creatively, regularly and continuously explore and discover new knowledge, theory, and the truth. So most fully meet each student's intellectual curiosity, thirst for knowledge and happiness to a whole new way of education and learning. Most commonly used C language software development tools, whether it is entertainment activities such as games, chat and get to the Internet, or all kinds of application systems and office software, can be completed by $\mathrm{C}$ language. C language level mainly consists of function, are independent of each other between each function, the $\mathrm{C}$ language development environment provides a number of commonly used 
functions, convenient software developer use directly. At the same time, the $\mathrm{C}$ language debugging and writing can be separately, either by many people work together to complete a task, and multiple editing tasks can be performed by one person. Thus, $\mathrm{C}$ language is a practical very strong software development tools. Combining interesting and practical, in turn the classroom teaching mode, applied in "C language program design" education, to achieve two goals: first, contact the students interested in practical problems, make the course more interesting, let students understand programs written in the real meaning of life, so as to reduce the difficulty of learning, enhance learning effect. Second, the ability of using a computer programming is the embodiment of computational thinking, students should not only master computer language grammar knowledge, it is important to understand the thoughts and methods of application design, improve the ability to analyze and solve problems.

\section{Existing Problems on C Language Course Teaching}

At present, many colleges and universities "C language program design" course still use the traditional teaching method, through language, blackboard writing, the picture and model to impart knowledge to students. Teachers always dominant and central position in teaching, mainly revolves around the teachers teaching activities, students of education as the object of the task is to accept knowledge, and form a cognitive structure. The traditional teaching method pays attention to scientific knowledge system, which help students form the knowledge structure and system in a short time. "Pass - accept" as the characteristics, emphasize the teacher's leading role, teachers can fully control the classroom, helps the student thought of concentration. Advocates the class teaching system, to facilitate teachers' organization and monitor the whole process of teaching activity. Can facilitate the emotional communication between teachers and students, fully considering the importance of emotional factors in learning, it is advantageous to the student language expression and will quality and the cultivation of the modal target, etc.

The traditional teaching method also has many advantages, but already could not adapt to the need of modern education teaching. On the training goal, only pay attention to impart knowledge, does not pay attention to the development ability, cultivate students according to the same mode, is not conducive to creative thinking and innovation ability of the growth of the creative talents. On the teaching content, teaching material is the only study contents, students are the main source of student knowledge. On teaching methods, is the injection and the non-computer majors, only teachers such as "teaching", do not take the students how to "learning", exam mainly by rote learning, is not conducive to mobilize students' learning enthusiasm. In the form of teaching, only one channel, simplification and estimation and ignore their aptitude and outside class channel. Effect on the relationship between teachers and students, outstanding teachers, teacher is the initiative of the instructors, ignore students' initiative, student is the object of knowledge, is the passive recipients of external stimulation. Traditional education is a conservative and closed. Under the guidance of the traditional education form the way of thinking, could not meet the students' development needs, also can't let students adapt to the needs of the development of era.

With traditional teaching method of "C language program design" course problems are as follows: "programming" and "language knowledge" improper handling of the relationship between simple speak the "language", students feel knowledge scattered, dull. Simply speak "programming", students will feel abstract, lack language knowledge; "Programming" and "programming thought" improper handling of the relationship between teachers' emphasis on "programming", focuses on the program list, along with the relevant "language knowledge", not "programming thought". Students can read the program from the implementation results, analysis and problem solving ability, lead to students will not develop software; Teaching process failed to reflect "integration of teaching", students can only passively accept not active participation, teaching process turns to be the teachers' individual performance, did not follow the students' cognitive law, not to let the students to master the process of "problem solving", is not conducive to the students to accept and grasp knowledge; "Running the debugger" teaching mishandled, students debugger ability is poor, problem analysis and algorithm design, programming and debugging is running three link of 
development program, teachers only to compile error, the basic concepts such as connection errors and logical errors and explain, ignore the logical error processing method, the result is the student not to debug the program.

\section{"Rotation classroom" Teaching Model}

"Turn the classroom" is inclusion earnestly, interaction and practice three teaching links, the three complement each other, be short of one cannot. Earnestly is one of the most important and students need to master content by the teacher. Speaking difficult, that is focused on, easy to mix, speak easy fault points, speak easy funneled points, speak easy to ignore. Speak at the same time, also want to do "three-no", namely the students themselves have will not speak, the student can learn to do not speak, the teacher tells the students how to also won't do not speak. Avoid students' knowledge in partial, fragmentary and incomplete. Earnestly teachers, students discuss again on this foundation, to deepen the understanding of the teaching content and absorption. Interaction refers to the discussion and communication between teachers and students and students, rather than simply teaching the teaching material content. Through interaction, on the one hand, students can learn from others can't absorb the course content, developing the thinking; On the other hand, it enables the teacher to fully grasp the depth and breadth of study, and targeted to teach classes. Practice refers to under the guidance of professional teachers, professional experiments and practice, to improve students' own actual hands-on ability. Teacher, in a timely manner to give professional guidance, and make an objective evaluation, timely release the evaluation results. "Transshipment class" is the core of the students, the teacher is the student to study the designers, instructor, helper and study partner. In this model, students and teachers promote each other and common development. "Turn the classroom" mainly includes five steps, as shown in Fig. 1.

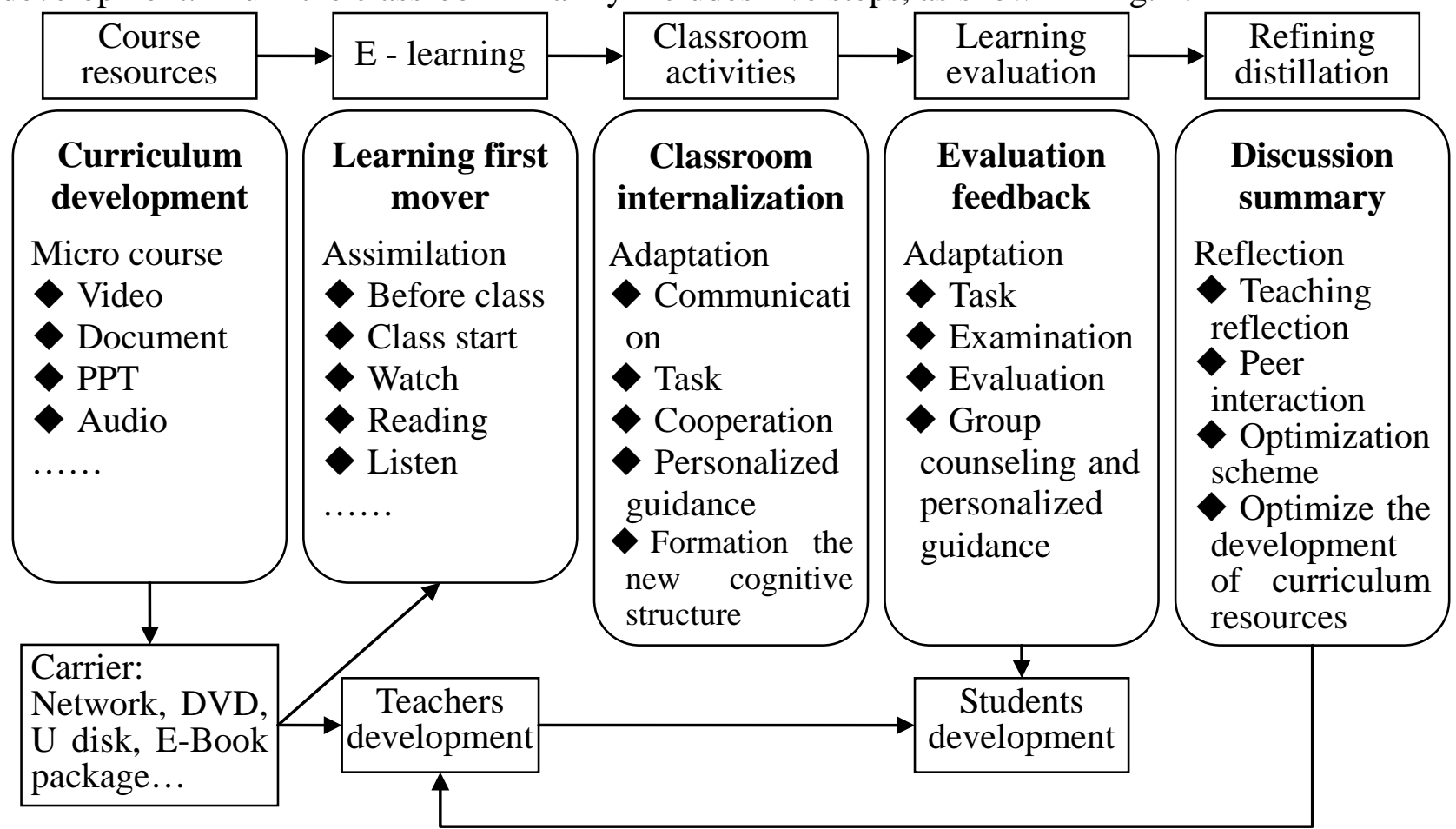

Fig.1. "Rotation classroom" teaching model

(1) Determine the problem, the teacher according to the course content and teaching students to watch video, practice before class put forward questions, come to the conclusion that some have to explore the problem of value;

(2) Independent exploration, the respect for the independence of the students throughout the class design, let the students construct their own knowledge system in independent learning;

(3) The collaborative learning, be helpful for developing students' individual thinking ability, enhance the communication between the student individual ability, and students mutual tolerance; 
(4) The results of communication, the form of communication can be varied, such as holding exhibitions, presentations, debates, and small game, etc.;

(5) Feedback evaluation, not only should pay attention to the learning results of evaluation, but also through the establishment of students' archives, to evaluate the learning process.

\section{Scheme on Teaching Reform and Practice}

Rotation classroom teaching activities requires teachers to have higher teaching ability, not only to mobilize students' thinking in the classroom, but also can quickly detect the student's confusion, real-time guidance or put forward rational solutions. Due to the students' active thinking, questions may be interdisciplinary, teachers need to have the discipline not only knowledge, but also increase the breadth of knowledge and the dimension, at the same time also need to have in the limited time to organize students to discuss and study ability. Teachers in the classroom teaching and practice teaching continuously to attract the attention from student inspire and cultivate the students' interest. Create good classroom teaching and practice teaching effect, lets the student interest in active learning, and get training and continue to interest. Introduction to basic idea is: interesting demonstration lead, the interest as a student the best lead; Issue the import type teaching method combined with interesting situation setting teaching methods, fully arouse the enthusiasm of students; Creating studying topic from easy to difficult, let students gain confidence, cultivate long-term interests; On or the main algorithm is applied to appear in the teaching material, in the later to focus on, to make the students know fairly well; Interesting design throughout the course of the teaching to develop students potential, cultivating students' thought. Specific plan is as follows:

(1) Learning case design. From the basic knowledge of language use, controls, control statements structure, array and pointer, function and file is divided into several learning module, the design of corresponding guiding cases for each module, to achieve better study effect, suitable for different levels of students, provide some student web site. For existing difficult point to communicate with teachers face to face, or application for network communication software. For mastering knowledge and writing skills program, students can learn by complete case task assigned by the teacher to verify the effect.

(2) The classroom teaching mode. The leading role of students is the classroom teaching mode, the teacher is the direction of the study guide. In class, the teacher to answer the problem of students self-study before class is for the opening, a discussion about 10 minutes, and then according to students' feedback information on doubt and difficulty, earnestly about 30 minutes, after the difficult to explain, teachers according to the case study on group discussion, avoid discussing learning become a mere formality, prevent the superficial learning process and superficiality, last modification and debugging the program and finally complete the study task. To urge the learning, the teacher can be drawn from each group of random 2 student collaboration shows, and explain the program task completion. Teachers for grading in groups as a unit, and release team ranking, mobilizing the unity cooperation spirit and motivation of learners.

(3) The design of practice teaching. Practice teaching is to consolidate theoretical knowledge and an effective way to deepen understanding of the theory, is to cultivate innovative high-quality engineering and technical personnel of the important link, is the theory with practice, cultivate the students master the scientific method and the important platform to improve the beginning ability, is conducive to the formation of students' quality improvement and the correct values. Through theoretical teaching, students have mastered the relevant knowledge, contact with the typical examples, and the interest in learning. Practice teaching aims to consolidate knowledge, strengthen the consciousness of cooperation, improved the ability to apply. With the method of grouping, each group of three to four people, as the practice teaching, group members can be readjusted according to the learning situation. Practice content can be a typical example, also can be the teacher according to the situation of students design and life issues, in order to improve the learning interest, the whole process is given priority to with students to discuss, the teacher answer is complementary.

(4) The study effect evaluation. The guiding ideology of evaluation is to promote the students the basic knowledge to master and improve the comprehensive quality and ability to program design. 
Use a variety of evaluation methods, the combination of specific include: the process of evaluation, student learning condition of data and information collected through, and according to the description of the learning condition is certain standards and judgment; Quantitative evaluation, the test scores at the end of the peace on schedule performance comprehensive evaluation of learning effect; Summative assessment, the end of the semester, according to the attendance, classroom performance, answer questions, homework completion, the final exam results, etc., comprehensive evaluation of the effect of learning; Other way to evaluate students to participate in the competition of process design and activities, such as certain achievements, can be used as a summative evaluation of the student.

\section{Conclusion}

"Rotation classroom teaching reform train of thought is presented in this paper the basic mature conditions and major trends, combined with the characteristics of" $\mathrm{C}$ language program design "course, aims to explore a suitable for" language $\mathrm{C}$ program design "course the rotation of the classroom teaching mode, the interesting case applied to the teaching practice of boring, and combined with practical, so as to stimulate students interest in learning, improve the comprehensive quality and ability of students. Specific role is: interesting "fragments" into knowledge and knowledge system combining "integration"; Increase between teachers and students and interaction between students and students, emphasize the personalized learning; Improve students' comprehensive quality and creative ability; Interest is the best teacher, interest in students' learning.

\section{Acknowledgement}

This work is supported by teaching reform project of Bohai university (bdjg15YBC021): Reform and practice of rotation classroom teaching on "C language program design" based on interesting and practical.

\section{References}

[1] H. L. Qiu, "C Language Teaching Reform and Explore of the Applied Universities," Yinshan Academic Journal (Natural Science Edition), vol. 35, no. 4, pp. 1-3, 2016.

[2] J. Xiao, H. R. Xiao, "Problems Analysis and Strategies Research in Teaching the Course of The C Language Programming," Journal of Dongguan University of Technology, vol. 20, no. 5, pp. 111-115, 2013.

[3] P. F. Zhang, X. L. Huang, "Organization and design of the teaching resources in the flipped classroom," Journal of HeBei United University (Health Sciences), vol. 15, no. 1, pp. 129-130, 2014.

[4] 360 personal library, "Learning acquisition evaluation," http://www.360doc.com/content/11/0525/18/5949809_119349640.shtml, 2016-9-5.

[5] Education Department of Liaoning Province, "The reform of classroom teaching mode in Bohai University: turning the classroom," http://www.lnen.cn/jyzx/yxxw/283452.shtml, 2016-9-5.

[6] Online document sharing platform, "Problems in C language teaching," http://www.doc88.com/p-2819725197802.html, 2016-9-5.

[7] W. Z. Lv, "Practice of teaching reform of C language program design in Higher Vocational Education," Computer Knowledge and Technology, vol. 12, no. 25, pp. 131-132, 2016.

[8] H. M. Guo, L. C. Zhan, "Carrying Interest through to the End in C Language Teaching: A Method of Enhancing the C Language Teaching Effect," Computer Knowledge and Technology, vol. 6, no. 28, pp. 8030-8032, 2010. 